\title{
Ovarian Hyperstimulation Syndrome: A Rare Case of Unilateral Pleural Effusion
}

\author{
Ali Sami Gurbuz', Mustafa Çalık², Emel Ebru Özcimen³ , Necati Özcimen4, Saniye Göknil Çalık \\ ${ }^{1}$ Novafertil IVF Center, Konya, Turkey \\ ${ }^{2}$ Department of Thoracic Surgery, Konya Training and Research Hospital, Konya, Turkey \\ ${ }^{3}$ Clinic of Obstetrics and Gynecology, Başkent University Konya Research and Application Hospital, Konya, Turkey \\ ${ }^{4}$ Medicana Konya IVF Center, Konya, Turkey \\ ${ }^{5}$ Department of Emergency Medicine, Konya Training and Research Hospital, Konya, Turkey
}

\section{ABSTRACT}

Introduction: Ovarian hyperstimulation syndrome (OHSS) is a rare, usually self-limiting, life-threatening iatrogenic complication. Pleural effusion is usually bilateral and seen in severe forms. Unilateral pleural effusion in OHSS is extremely rare. Here, we present a patient with unilateral pleural effusion due to OHSS.

Case Report: A 30-year-old woman with a history of infertility for 5 years and no significant past medical history or physical findings applied to an in vitro fertilization (IVF) center. Ovarian stimulation was initiated. She was admitted with complaints of dyspnea on the second day that she was $\beta$-human chorionic gonadotropin ( $\beta$-hCG)-positive. She had tachypnea and decreased breath sounds. All laboratory tests were within the normal range. Ultrasonography evaluation demonstrated right pleural effusion without intraperitoneal fluid. Thoracentesis was performed, and 3000 cc exudative fluid was drained.

Conclusion: The number of patients who undergo infertility treatment at IVF centers has been increasing. Although OHSS is considered as if it is a syndrome that belongs to gynecology and obstetrics clinics or IVF units, the chances of clinicians who work in the emergency service and thoracic diseases and thoracic surgery centers encountering these patients have increased. Therefore, it should be kept in mind that there may be unilateral pleural effusion without peritoneal fluid in OHSS.

Keywords: Ovarian hyperstimulation syndrome, OHSS, pleural effusion

Received: 30.11.2015 Accepted: 19.02.2016 Available Online Date: 14.06.2016

\section{Introduction}

Infertility is defined as the failure to conceive after 1 year of regular intercourse in women $<35$ years of age not using contraception and after 6 months in women $>35$ years. The incidence of infertility varies among different populations studied; data from population-based studies suggest that 10\%-15\% of couples in the Western world experience infertility. It is estimated that as many as 80 million couples are affected by infertility worldwide. Assisted reproductive technology (ART) such as IVF and embryo transfer (ET) has been essential in the treatment of infertility $(1,2)$. Ovarian hyperstimulation syndrome (OHSS) is the most serious, potentially lethal iatrogenic complication of controlled ovarian stimulation, which occurs in 33\% of ovarian stimulation cycles with clinical manifestations varying from mild to severe as part of ART. The incidence of OHSS varies according to different classification methods. Its pathogenesis is unknown, but an increase in vascular permeability and third-spacing, leading to hemoconcentration and inadequate end organ perfusion is thought to be the main pathophysiology of OHSS. However, severe OHSS, which is generally accompanied by significant ascites acidosis, seldom leads to pleural effusion (10\%). In the literature, unilateral pleural effusion due to OHSS is rarely reported $(3,4)$. Here, we present a patient with unilateral pleural effusion due to OHSS.

This study was presented as a poster presentation in the American College of Chest Physicians (CHEST) Meetings, 24-28 October 2015, Montréal, Canada.

Address for Correspondence:

Mustafa Çalık, Department of Thoracic Surgery, Konya Training and Research Hospital, Konya, Turkey

E-mail: drmcalik@hotmail.com

oCopyright 2016 by Emergency Physicians Association of Turkey - Available online at www.jemcr.org 


\section{Case Report}

A 30-year-old G0 woman with a history of infertility for 5 years and no significant past medical history or physical findings applied to an IVF center. On the second day of the menstrual cycle there were 11 antral follicles on each ovary and the levels of follicle-stimulating hormone (FSH), luteinizing hormone, and estradiol (E2) were 5.28 $\mathrm{mIU} / \mathrm{mL}, 2.12 \mathrm{mlU} / \mathrm{mL}$, and $20 \mathrm{pg} / \mathrm{mL}$, respectively. The spermiogram parameters were within the normal range.

Ovarian stimulation was initiated with $225 \mathrm{IU}$ of recombinant FSH (rFSH) for 5 days. This dose was increased to $300 \mathrm{IU}$ on the fifth day because of low levels of E2 and low ovarian response. On the $10^{\text {th }}$ day of induction there were two follicles that reached $20 \mathrm{~mm}$ and $18 \mathrm{~mm}$. Her peak E2 level was $1733 \mathrm{pg} / \mathrm{mL}$. Then, 10,000 IU urinary human chorionic gonadotropin (hCG) was injected and oocyte pickup (OPU) was performed at the $36^{\text {th }}$ hour. A total of 12 oocytes were retrieved. One embryo transfer (ET) was performed on the third day of OPU.

On the $12^{\text {th }}$ day of ET the $\beta$-hCG level was $278 \mathrm{IU} / \mathrm{mL}$. She was admitted with complaints of dyspnea on the second day that she was $\beta$-hCG-positive. She was afebrile but tachycardic. She had 2 kg weight gain. Oxygen saturation on room air was $97 \%$. She had shortness of breath, cough, and chest pain. She had tachypnea and decreased breath sounds. Her echocardiography and electrocardiography (ECG) were within the normal range. She did not have nausea, vomiting, or abdominal distension.

Abdominal ultrasound evaluation demonstrated no evidence of intraperitoneal fluid and the ovaries were enlarged bilaterally (right: $50 \times 85 \mathrm{~mm}$; left: $52 \times 89 \mathrm{~mm}$ ). She had normal liver and renal function tests. Her electrolytes were also normal and her hematocrit was 42\%.

Because of her pregnancy, the patient and her family refused chest $X$-ray and computed tomography, and ultrasound examination revealed right pleural effusion (Figure 1). There was minimal pleural effusion on the left side. It was in a restricted area and had millimeter dimensions (Figure 2). Thoracentesis was performed on the right side; nearly 1500 cc yellow fluid was initially suctioned and then 3000 cc fluid was drained via a pigtail catheter over 3 days. The fluid was exudative and contained $40 \mathrm{~g} / \mathrm{L}$ protein. During the patient's physical examination no symptom or finding in the direction of empyema, deep vein thrombosis (DVT), or pulmonary embolism was encountered. Pleural fluid culture, acid fast, and Gram stain were negative. Pleural fluid cytology was negative for malignancy. ECG, echocardiography, bilateral lower extremity venous Doppler ultrasonography, and bilateral Homans' signs were negative. Lowmolecular-weight heparin for the prophylaxis of DVT was injected.

Abdominal ultrasound was performed daily and no fluid was observed. After 3 days her dyspnea and cough resolved and the $\beta$-hCG value was $1285 \mathrm{IU} / \mathrm{mL}$. The pigtail catheter was removed without complications. The patient was discharged 2 days after the pigtail catheter was removed and was followed closely as an outpatient with serial ultrasound for her pleural effusion and dyspnea. She fully recovered without sequelae. Now, she has an uncomplicated singleton pregnancy at 9 weeks of gestation.

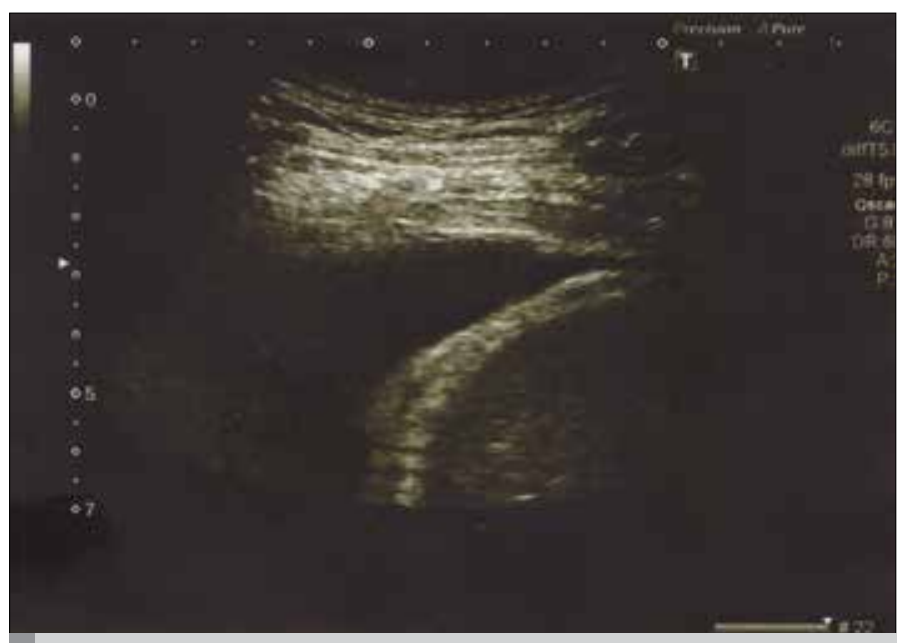

FIGURE 1. Ultrasound imaging shows massive right-side pleural effusion

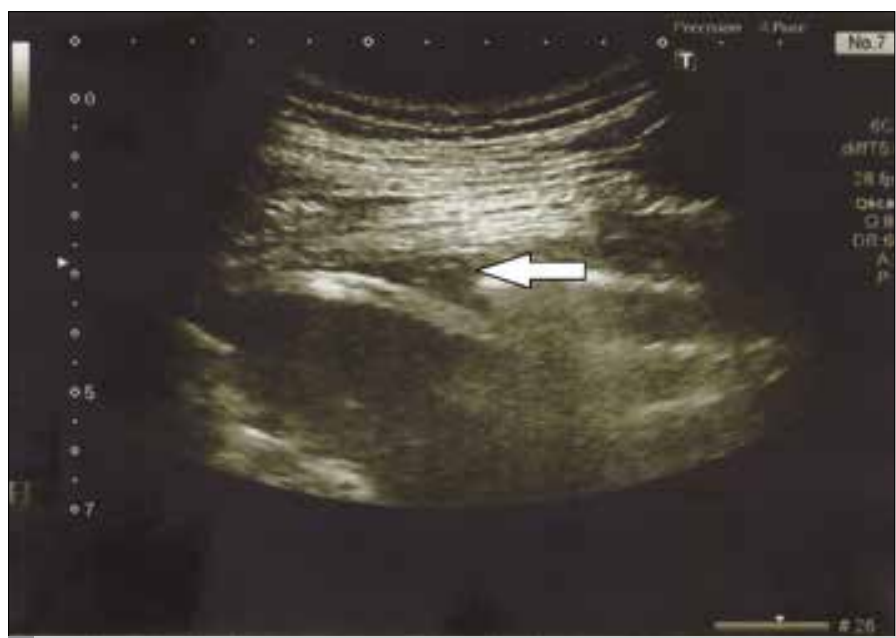

FIGURE 2. Ultrasound imaging shows minimal left-side pleural effusion in a restricted area of millimeter dimensions (white arrow).

\section{Discussion}

Although it varies depending on the level, the pleural cavity has a width of approximately 18-20 $\mu \mathrm{m}$. The pleural membranes do not touch each other, which makes it a real gap, not a potential space. Classically, pleural effusion is the accumulation of fluid in the pleural cavity, which may be caused by any reason (5). OHSS is a rare, usually self-limiting, life-threatening iatrogenic complication $(3,4)$. In 1975, unilateral pleural effusion in OHSS was first described (6). The risk factors for OHSS are: young age, low body mass index, polycystic ovary syndrome, increased E2 levels, a previous history of the presence of OHSS, hypothyroidism, multiple pregnancy, and molar pregnancy (7). OHSS is classified as mild, moderate, severe, or critical. Mild manifestations of OHSS are relatively common in induced cycles and include abdominal distension, mild nausea, vomiting, and diarrhea $(3,4)$. With progression of the illness pleural and pericardial effusion can be observed, which are regarded as severe OHSS (8). Our case was classified as severe despite the lack of acidosis, dyspnea, and right pleural effusion. Severe OHSS has been reported in less than $2 \%$ of patients who require hospitalization. Early OHSS is 
correlated to ovarian response to stimulation and is an acute effect of the administration of exogenous hCG that usually occurs within 9 days after oocyte retrieval. In contrast, late OHSS occurs after the initial 10 day period, is only poorly correlated to ovarian response, and is more correlated to the endogenous hCG produced by an implanting embryo (9). The main aim of the induction of ovulation is to achieve pregnancy, but if pregnancy occurs OHSS tends to be more severe and may last longer.

Although its pathophysiology is not known exactly, an increase in capillary permeability, fluid accumulation in a third space caused by this increase, and inadequate organ perfusion are suspected. Vascular endothelial growth factor (VEGF), components of the renin-angiotensin system, prostaglandin, and cytokines such as interleukin (IL)-6 and IL-8 play a role in its etiopathogenesis. Capillary permeability is reduced by $70 \%$ by the administration of VEGF antibodies, which is considered the most essential factor (10).

Holes in the diaphragm and negative intrapleural pressure may draw fluid from the abdomen to the thoracic cavity (3). It is easy to assume that bilateral pleural fluid is caused by acid. However, it is hard to explain unilateral pleural fluid. Although its pathogenesis is controversial, it is attributed to the fact that lymphatic drainage on the right side is less compared with on the left side, and holes in the diaphragm occur more often on the right side $(3,10)$. In our case, pleural fluid was on the right side and there was no acid in the abdomen. She recovered by pleural drainage and supportive therapy.

In the literature pleural effusion may be exudative, as in our case, or transudative (9). Because of our patient's pregnancy, a chest Xray could not be performed but ultrasound helped us to diagnose pleural effusion. In the literature there are reports about the use of ultrasound in pleural effusion $(3,4,9)$. Also, ultrasound can detect as little as $5 \mathrm{~mL}$ pleural fluid (5). In our case, left pleural effusion was detected, even though it was of millimeter dimensions, by ultrasound.

In our case, although there was a large amount of pleural effusion, no other significant markers of severe OHSS were present. If only the abdominal cavity is examined, pleural effusion could easily be overlooked. A good complete examination of an OHSS patient, early diagnosis, adequate pleural drainage, and then good supportive therapy make the prognosis of OHSS favorable.

\section{Conclusion}

As a result, the number of cases resorting to the treatment of infertility and the number of centers where it is employed have been increasing (3). Although OHSS is considered as if it is a syndrome that belongs to gynecology and obstetrics clinics or IVF units, the chances of clinicians who work in the emergency service and thoracic diseases and thoracic surgery centers encountering these patients have increased. Therefore, it should be kept in mind that there may be unilateral pleural effusion without peritoneal fluid in OHSS.

Informed Consent: Written informed consent was obtained from patient who participated in this case.

Peer-review: Externally peer-reviewed.

Author contributions: Concept - A.S.G., M.Ç., S.G.Ç.; Design - M.Ç., S.G.Ç.; Supervision - M.Ç., S.G.Ç.; Resource - M.Ç., S.G.Ç.; Materials - M.Ç., S.G.Ç.; Data Collection \&/or Processing - M.Ç., E.E.Ö.; N.Ö., S.G.Ç.; Analysis \&/or Interpretation - M.Ç., E.E.Ö., N.Ö., S.G.Ç.; Literature Search - M.Ç., E.E.Ö., S.G.Ç.; Writing - M.Ç., E.E.Ö., S.G.Ç.; Critical Reviews - M.Ç., S.G.Ç.

Conflict of Interest: The authors declared no conflict of interest.

Financial Disclosure: The authors declared that this study has received no financial support.

\section{References}

1. Weiss RV, Clapauch R. Female infertility of endocrine origin. Arq Bras Endocrinol Metabol 2014; 58: 144-52. [CrossRef]

2. Adegbola $\mathrm{O}$, Akindele MO. The pattern and challenges of infertility management in Lagos, Nigeria. Afr Health Sci 2013; 13: 1126-9 [CrossRef]

3. Fiedler K, Ezcurra D. Predicting and preventing ovarian hyperstimulation syndrome (OHSS): the need for individualized not standardized treatment. Reprod Biol Endocrinol 2012; 10: 32. [CrossRef]

4. Fatemi HM, Popovic-Todorovic B, Humaidan P, Kol S, Banker M, Devroey $\mathrm{P}$, et al. Severe ovarian hyperstimulation syndrome after gonadotropinreleasing hormone (GnRH) agonist trigger and "freeze-all" approach in GnRH antagonist protocol. Fertil Steril 2014; 101: 1008-11. [CrossRef]

5. Esme H, Calik M. Management of Malignant Pleural Effusion, Principles and Practice of Cardiothoracic Surgery, Dr. Michael Firstenberg (Ed.), InTech 2013, ISBN: 978-953-51-1156-6.

6. Soydinç HE, Evsen, MS, Sak ME, Gül, T. Gebelikte Asitin Nadir Spebebi: Spontan ovaryan hiperstimülasyon sendromu. Van Tıp Dergisi 2012; 19: 86-9.

7. Junqueira JJ, Bammann RH, Terra RM, Pugliesi de Castro AC, Ishy A, Fernandez A. Pleural effu-sion following hyperstimulation. J Bras Pneumol 2012; 38: 400-3. [CrossRef]

8. McNeary M, Stark P. Radiographic findings in ovarian hyperstimulation syndrome. JThorac Imaging 2002; 17: 230-2. [CrossRef]

9. Rabinerson D, Shalev J, Royburt Z, Ben Rafael, Dekel A. Severe unilateral hydrothorax as the only manifestation of the ovarian hyperstimulation syndrome. Gynecol Obstet Inves 2000; 49: 140-2. [CrossRef]

10. Chen CD, Wu MY, Chao KH, Lien YR, Chen SU, Yang YS. Update on management of ovarian hy-perstimulation syndrome. Taiwan J Obstet Gynecol 2001; 50: 2-10. [CrossRef] 